\title{
ROLE OF COLORS IN DESIGN WEB BANNER ADVERTISING: IN THE CONTEXT OF ETHNIC APPAREL
}

\author{
Ankita Majumdar \\ Research Scholar \\ Dept. of History of Arts, Faculty of Arts, B.H.U, Varanasi
}

\section{INTRODUCTION}

Since the first banner ad spanned the top of the Hot Wired web site in 1994, and internet advertising expenditures have seen triple digit growth to around three billion dollars per year. Although limited in size to 468 by 60 pixel, banner ads are the main form of advertising on the web and today's scenario it is one of the most prolific form of marketing used in online world. All companies use them in one form or another because they are an affordable, measurable and effective medium to increase Brand awareness and Brand equity. The web is a colorful place, and there is a lot that can be accomplished by using color in the right way, at the right time, with the right audience, and for the right purpose. Therefore it turns out that color is one of the most exciting things in the world.

Since in the beginning colors have stirred our emotions. White chalk was a precious tool in the hand of Paleolithic artists. Gold from the very first civilization reminded us of the sun. A desire for the mysterious and exotic blue changed the course of history. Similarly in the modern period especially in advertising world, colors are always an important element of design for communication. It is the first thing that viewers notice in ads and today's scenario the web is a global medium for advertising and as such it requires as to consider the meaning of color in a much broader context. Since the beginning of the digital revolution we have free to access any color, we can possibly think of and more and more people access the web with high quality color monitors. Therefore colors and color graphics are important dimensions in the design of web banner advertising. Colors are definitely grabbing worldwide attention, but it certainly was not easy to get hold of. This is why it became the ultimate symbol of luxury. Those who could afford it use favorite hues to decorate their surroundings. That's why color is powerful element of design, it can change our mood- the mood of potential customers. If a color of web banner ads improves our state of mind, our relationship with a brand will deeper and probability of return and click through rate will increase. So it means the color make the advertising attractive and evoke the consumer desire towards the ads. Thus this paper will going to discuss the role of color in web banner advertising in context of ethnic apparel and also understanding colors and how they can be used to enhance visual communication in banner ad design.

\section{COLOR PSYCHOLOGY IN BANNER ADVERTISING}

Color wields enormous sway over our attitude and emotions. When our eyes takes in a color, they communicate with a region of the brain known as the hypothalamus, which in turn sends a cascade 
of signals to the pituitary gland, on to the endocrine system and then to the thyroid glands. The thyroid glands signal the release of hormones, which cause fluctuation in mood, emotion and resulting behavior. In advertising colors are more important than the actual wording of the ads. The reason for this is that colors and graphics capture consumer attention then causes them to read your ads. According to psychology.about.com, psychologist has suggested that color impression can account for $60 \%$ of the acceptance or rejection of that product or service. The national origin of potential buyers, for example, can influence their preference for color.

It has said that design elements might be closely relate to consumer's emotion on the web, and also found that design elements such as content and color are critical factors in consumer decision making or in other internet interface behaviors color is an important creative tool with potential.Lifestyle preference can also influence which colors are favored. Vivid primary colors, such as red and blue, use along with white strips are representative of an active lifestyle. So as example we can see that as lifestyle such as ethnic apparel for women's is very sensitive area. Women's are very sophisticated for her lifestyle. Now an ethnic wear has been making headline on global fashion circuits for quite some time. Due its attractive and eye-catching design and sheer beauty of these outfits it has attained huge popularity in today's women's life and has once again stormed Indian markets. On the basis of these ethnic apparel is not only taking place in offline market also it is in great demand in online market. Designing ads for ethnic apparel in internet is very challenging for designers. Designers have thought alot to design the advertising especially in the time of color selection. In ethnic apparel advertising color play an important and essential role, because color instinct consumer towards product. So while designing banner ads for ethnic apparel advertiser and designer are well aware of that. Designer has to know that what color scheme used in ethnic apparel ads, because disagreements in the perception of colors depends on origin, age, gender and even state of health. Vivid and bright colors are popular among the youth, while older people feel more comfortable when surrounded by subdued shades. Color harmony is also very important in advertising, because color can be defined as a pleasing arrangement of parts in design. In visual experience harmony is something that is pleasing to the eye. It engages the viewer and it creates an inner sense of order, a balance in the visual experience. In advertising through colors designer can control reactions of an audience and provoke them to certain behavior. Similarly for ethnic apparel advertising designer used different color according to the product images and describe their impact on users which are as follows:-

\section{Warm bright colors}

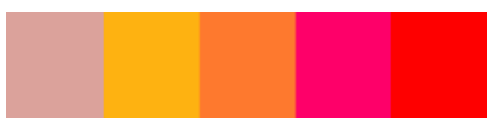

cold dark colours

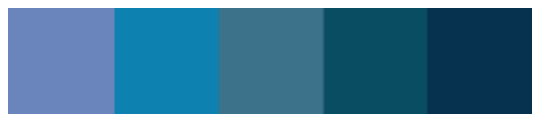

Beige, yellow, orange, pink, red and similar. These are active, eye-catching colors with a friendly nature that may induce a sense of courage and energy. Warm bright colors visually enlarge objects and make them seem closer. Red color for ethnic apparel advertising associated with passion, \& excitement. Orange color is the great color for call to action button. 


\section{Cold dark colors}

Violet, blue, turquoise, green, navy give a feeling of stability and quality. These shades are often placed as accompanying colors. Although they don't attract attention they emphasize the content. Cold dark colors are widely used on festive seasons like Christmas, New Year, etc. Designer used the cold colors to show the effects of snow and scenario of snowy and cold atmosphere.

\section{Warm dark colors}

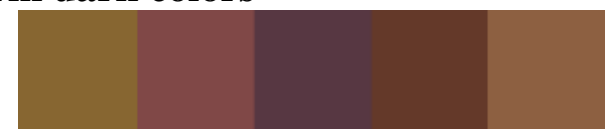

Gold, purple, brown express classics, tradition, luxury and relaxation. They blend well in expensive and elegant designs for young and rich. Mixed with cold colors give an impression of modernity and novelty.

\section{Neutral colors}

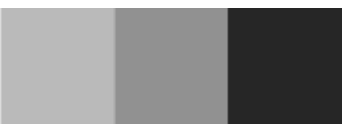

White, grey and black help to create contrasts and bring all the other colors out. They don't convey any particular message on their own. Neutrals are here to support their neighbors by playing the role of complementation on web banner advertising.

Designer apply colors in banner advertising by correlated the color for their impact in advertising, like Reddish-brown sepia tones refers to past and tradition, navy- blue combination are associated with dynamism, while black and white in equal amounts give deeper expression to each other. The simplest set of colors expresses thoughts without words and influence audience. The choice of these colors should reflect the brand mission with strength and clarity, so that it can attract prospective customers. Warm colors impact users to take action, whitest cold shades have cooling effect; red spot on a light background is expressive, while placed on a cold one is almost hot. In banner advertising we can see mostly that offers are generally seen in red because it provoke the consumer and peruse them to click on it. Designer used complimentary colors to enhance the product and also sometimes monochrome color to balance the product with background. In banner advertising design there is a line that "The Stronger the contrast, the more powerful the message."

\section{CONCLUSION}

From the above discussion in the web, with its combination of computer screen, color encoding standards and color specification in web banner, constitutes a distinct medium for the presentation and manipulation of color. Mastery of color on the Web requires a combination of artistic and programming abilities. As you develop your own websites, keep in mind that color is subjective and color choices will probably be made in collaboration with your clients. Contrast in value, as 
well as color, Plays an important role in design. Trust your intuition as well as theoretic knowledge when applying color, and remember that color is just one of the factors in your design. It should not be used to simply lenhance" black and white forms. It should add something meaningful to your message such as setting the mood, introducing cultural meaning, or connecting through spontaneous associations with your viewers.

\section{REFERENCES}

1. Bruce A. Huhmann "Visual Complexity in Banner Ads: The Role of Color, Image Type, and Animation. "University of Manitoba.

2. Anderson, John R. (1985), Cognitive Psychology and Its Implications, New York: Freeman.

3. Briggs, Rex and Nigel Hollis (1997), "Advertising on the Web: Is There Response Before ClickThrough?” Journal of Advertising Research, 37 (March/April), 33-45.

4. Li, Hairong and Janice L. Bukovac (1999), "Cognitive Impact of Banner Ad Characteristics: An

Experimental Study, ” Journalism and Mass Communication Quarterly, 76 (Summer), 341-353.

5. Meyers-Levy, Joan and Laura A. Peracchio (1995), "Understanding the Effects of Color: How the Correspondence between Available and Required Resources Affect Attitudes,"

Journal of Consumer Research, 22 (September), 121-138.

6. Starch, Daniel (1923), Principles of Advertising, Chicago: A. W. Shaw.

7. Rebecca Creger. "14 design tips for more clickable banner ads." 14. August. 2014.10.Nov.2014< https://www.google.co.in/search /14 design tips for more clickable banner ads.htm>

8. Lister Jonathan, "How Does Color Affect Advertising?", Demand Media.< http://smallbusiness.chron.com/color-affect-advertising-30998.html>

9. Kaminska Paula, "The Impact of Color in Advertising, Marketing, and Design." 14. october. $2014<$ http://www.blurgroup.com/blogs/group/the-impact-of-colour-in-advertising-marketingand-design/> 